$16^{\text {th }}$ International Conference on

AEROSPACE SCIENCES \& AVIATION TECHNOLOGY,

ASAT - 16 - May 26 - 28, 2015, E-Mail: asat@ mtc.edu.eg

Military Technical College, Kobry Elkobbah, Cairo, Egypt

Tel : +(202) 24025292 - 24036138, Fax: +(202) 22621908

\title{
ECG Noise Canceller: Studying and Performance Improvement under Different Algorithms
}

\author{
Ashraf A. M. Khalaf ${ }^{*}$, M. M. Ibrahim ${ }^{\dagger}$, Hesham F. A. Hamed ${ }^{\ddagger}$ and M. A. Abdelghany ${ }^{\S}$
}

\begin{abstract}
In Electrocardiogram (ECG) application, we face a main problem of power line noise added to the ECG signal. Different Researchers have been interested in this problem due to its importance. In this paper we introduce a study of different algorithms and their effects on the performance of the ECG noise canceller. We have used many kinds of algorithms such as: LMS (Least Mean Square), NLMS (Normalized Least Mean Square), Signed Regressor LMS (SRLMS), Sign LMS (SLMS), Sign-Sign LMS (SSLMS) and a new proposed modified LMS called Variable Step size Least Mean Square (VSLMS) using MATLAB software package as well as Unbiased Linear output Neural Network (ULNN) and Unbiased Non Linear output Neural Network (UNLNN). It is promising to clarify the difference among these algorithms with the aim of obtaining better performance.
\end{abstract}

Keywords: ECG signal, adaptive noise canceller, neural network, power line interference

\section{Introduction}

Heart related problems are increasing day by day and Electrocardiogram (ECG) signal are very important in diagnosis of heart related problems. There are various artifacts which get added in these signals and change the original signal therefore there is a need of removal of these artifacts from the original signal. ECG signals are very low frequency signals of about $0.5 \mathrm{~Hz}-100 \mathrm{~Hz}$. The low frequency signal is destroyed by power line interference of $50 \mathrm{~Hz}$ noise, this noise is also source of interference for biomedical signal recording. The frequency of power line interference $50 \mathrm{~Hz}$ is nearly equal to the frequency of ECG, so this $50 \mathrm{~Hz}$ noise can destroyed the output of ECG signal. One way to remove the noise is to filter the signal with a notch filter at $50 \mathrm{~Hz}$. However, due to slight variations in the power supply to the hospital, the exact frequency of the power supply might (hypothetically) wander between $47 \mathrm{~Hz}$ and $53 \mathrm{~Hz}$. A static filter would need to remove all frequencies between $47 \mathrm{~Hz}$ and $53 \mathrm{~Hz}$, Which could excessively degrade the quality of the ECG [1]. The adaptive filtering has become one of the effective and popular approaches for the processing and analysis of the biomedical signals such as ECG signal.

\footnotetext{
* Department of Communication \& Electronics, Faculty of Engineering, Minia University, ashraf.khalaf@mu.edu.eg.

$\dagger$ Department of Communication \& Electronics, Faculty of Engineering, Minia University, mostafaelsaygh_2009@yahoo.com.

* Department of Communication \& Electronics, Faculty of Engineering, Minia University, Hfah66@yahoo.com.

$\S$ Department of Communication \& Electronics, Faculty of Engineering, Minia University, abdelghany@ mu.edu.eg.
} 


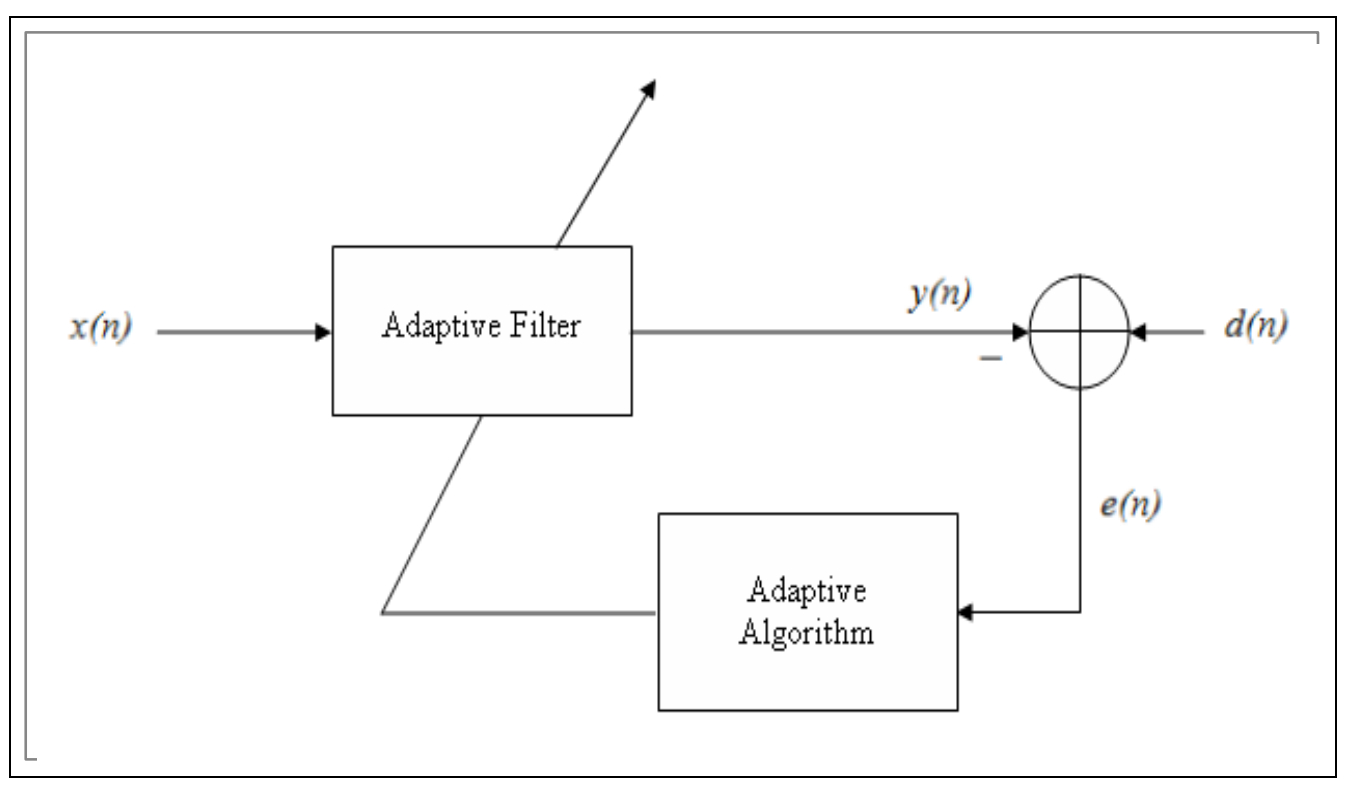

Fig. 1. General Adaptive filter

An adaptive filter has the property of self-modifying its frequency response to change the behavior in time, allowing the filter to adapt the response to the input signal characteristics change. Due to this capability, the overall performance and the construction flexibility, the adaptive filters have been employed in many different applications, some of the most important are: telephonic echo cancellation, radar signal processing, navigation systems, communications channel equalization and biomedical signals processing [2-5].The most common adaptive filters, which are used during the adaption process, are the finite impulse response (FIR) types. Figure 1 illustrates the general Adaptive filter [6].

The basic idea for the adaptive filter is to predict the amount of noise in the primary signal, and then subtract that noise from it. The prediction is based on filtering the reference signal $\mathrm{x}(\mathrm{n})$, which contains a solid reference of the noise present in the primary signal. The noise in the reference signal is filtered to compensate for the amplitude, phase and time delay, and then subtracted from the primary signal. This filtered noise is the system's prediction of the noise portion of the primary signal $y(n)$. The resulting signal is called error signale(n), and it presents the output of the system. Ideally, the resulting error signal would be only the desired portion of the primary signal [5].

In this work we investigate the performance of various adaptive algorithms and their effects on the performance of the ECG noise canceller and calculate the Mean Square Error (MSE) under different Signal to Noise Ratio (SNR).

\section{Adaptive Noise Cancellation}

Adaptive Noise Cancellation (ANC) is an alternative technique of estimating signals corrupted by additive noise or interference. Its advantage lies in that, with no apriori estimates of signal or noise, levels of noise rejection are attainable that would be difficult or impossible to achieve by other signal processing methods of removing noise. 


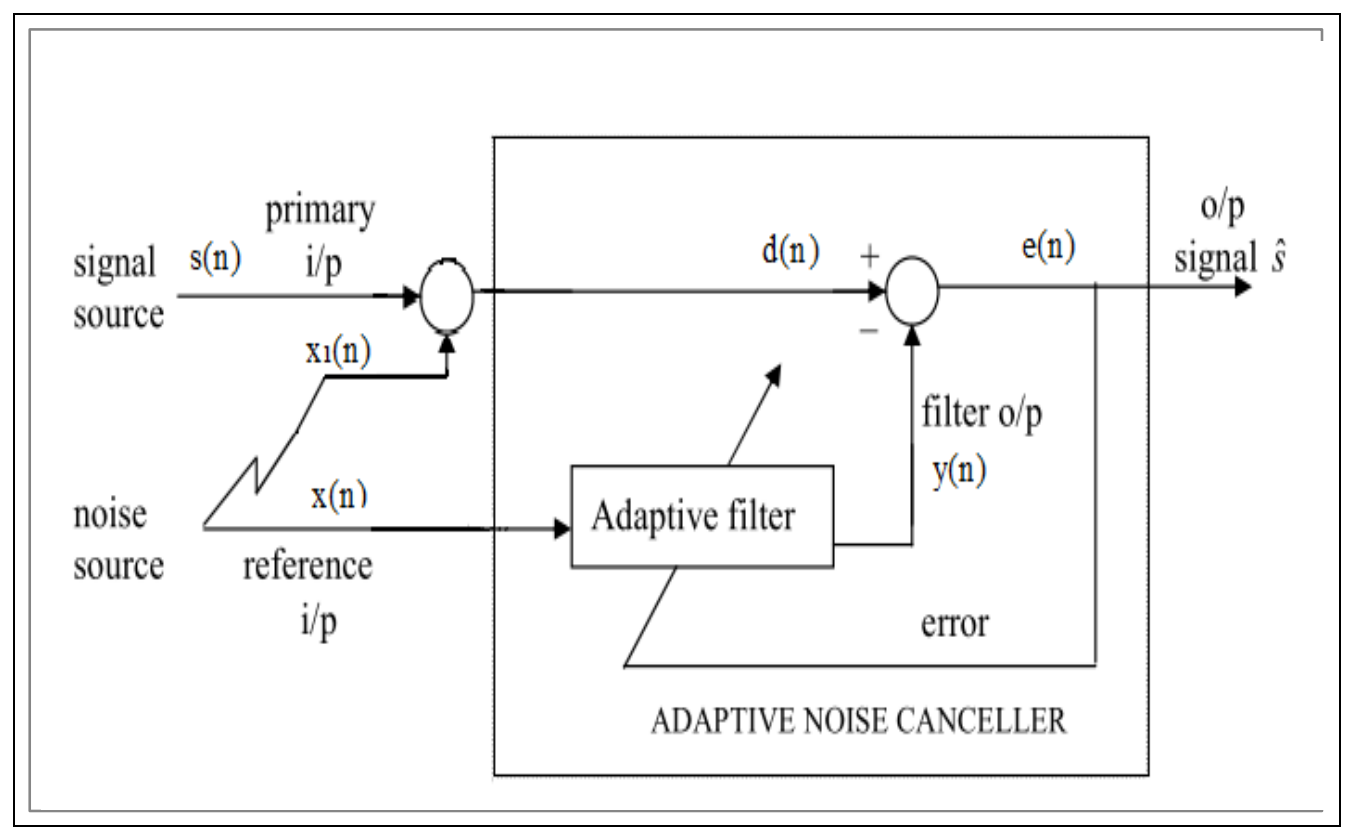

Fig. 2. Adaptive Noise Cancellation system

The ANC system has two inputs - primary and reference. The primary input receives a signal $\mathrm{s}(\mathrm{n})$ from the signal source or ECG signal source that is corrupted by the presence of noise $\mathrm{x}_{1}(\mathrm{n})$ uncorrelated with the signal. The reference input receives a noise $\mathrm{x}(\mathrm{n})$ uncorrelated with the signal but correlated in some way with the noise. The noise $\mathrm{x}(\mathrm{n})$ passes through a filter to produce an output $\mathrm{y}(\mathrm{n})$ that is a close estimate of primary input noise. This noise estimate $\mathrm{y}(\mathrm{n})$ is subtracted from the corrupted signal $d(n)$ to produce an estimate of the signal at $(n)$, the ANC system output which is supposed to be the same or very similar to primary signal $\mathrm{s}(\mathrm{n})$ [7]. Figure 2 shows adaptive noise canceling system.

\section{Adaptive Learning Algorithms}

A. LMS Algorithm

The LMS algorithm is a method to estimate gradient vector with instantaneous value. It changes the filter tap weights so that $\mathrm{e}(\mathrm{n})$ is minimized in the mean-square sense. The conventional LMS algorithm is a stochastic implementation of the steepest descent algorithm. It simply replaces the cost function $\xi(n)=E\left[e^{2}(n)\right]$ by its instantaneous coarse estimate.

The error estimation $\mathrm{e}(\mathrm{n})$ is

$e(n)=d(n)-w(n) x(n)$

Coefficient updating equation is

$\mathrm{w}(\mathrm{n}+1)=\mathrm{w}(\mathrm{n})+\mu \mathrm{x}(\mathrm{n}) \mathrm{e}(\mathrm{n})$

Where $\mu$ is an appropriate step size to be chosen as $0<\mu<0.2$ for the convergence of the algorithm. $\mu$ controls the stability and convergence speed of the LMS algorithm. The larger step sizes make the coefficients to fluctuate wildly and eventually become unstable. The most important members of simplified LMS algorithms are: 
B. SRLMS Algorithm

The signed regressor algorithm is obtained from the conventional LMS recursion by replacing the tap-input vector $x(n)$ with the vector $\operatorname{sgn}\{x(n)\}$.Consider a signed regressor LMS based adaptive filter that processes an input signal $\mathrm{x}(\mathrm{n})$ and generates the output $\mathrm{y}(\mathrm{n})$ as per the following:

$$
y(n)=w^{t}(n) x(n)
$$

Where, $w(n)=\left[w_{0}(n), w_{1}(n), \ldots, w_{L-1}(n)\right]^{t}$ is $L-t h$ a order adaptive filter. The adaptive filter coefficients are updated by the Signed-regressor LMS algorithm as,

$$
\mathrm{w}(\mathrm{n}+1)=\mathrm{w}(\mathrm{n})+\mu \operatorname{sgn}\{\mathrm{x}(\mathrm{n})\} \mathrm{e}(\mathrm{n})
$$

Because of the replacement of $x(n)$ by its sign, implementation of this recursion may be cheaper than the conventional LMS recursion, especially in high speed applications such as biotelemetry these types of recursions may be necessary.

\section{SLMS Algorithm}

This algorithm is obtained from conventional LMS recursion by replacing e(n) by its sign. This leads to the following recursion:

$$
\mathrm{w}(\mathrm{n}+1)=\mathrm{w}(\mathrm{n})+\mu \mathrm{x}(\mathrm{n}) \operatorname{sgn}\{\mathrm{e}(\mathrm{n})\}
$$

\section{SSLMS Algorithm}

This can be obtained by combining signed-regressor and sign recursions, resulting in the following recursion:

$$
\mathrm{w}(\mathrm{n}+1)=\mathrm{w}(\mathrm{n})+\mu \operatorname{sgn}\{\mathrm{x}(\mathrm{n})\} \operatorname{sgn}\{\mathrm{e}(\mathrm{n})\}
$$

Where $\operatorname{sgn}\{$.$\} is well known signum function, e(n)=d(n)-y(n)$ is the error signal. The sequence $d(n)$ is the so-called desired response available during initial training period. However the sign and sign - sign algorithms are both slower than the LMS algorithm. Their convergence behavior is also rather peculiar. They converge very slowly at the beginning, but speed up as the MSE level drops [8].

\section{E. NLMS Algorithm}

In NLMS, the step size takes the form of [8],

$$
\mu(\mathrm{n})=\frac{\alpha}{\mathrm{c}+\|\mathrm{x}(\mathrm{n})\|^{2}}
$$

Where: $\alpha$ is the NLMS adaption constant, which optimize the convergence rate of the algorithm and should satisfy the condition $0<\alpha<2$, and $\mathrm{c}$ is the constant term for normalization and is always less than 1 .

In NLMS algorithm, the filter weights are updated by 
$\mathrm{w}(\mathrm{n}+1)=\mathrm{w}(\mathrm{n})+\frac{\alpha}{\mathrm{c}+\|\mathrm{x}(\mathrm{n})\|^{2}} \mathrm{x}(\mathrm{n}) \mathrm{e}(\mathrm{n})$

\section{F. New Proposed modified LMS Algorithm}

The principle means of comparison is the error cancellation capability of the methods. This property depends on a few parameters, such as: step size for the LMS algorithm, therefore the LMS algorithm with variable step size is used. The step is adjusted with the increase in the number of iteration to match with the convergence of adaptive filter. The effect of this algorithm is compared with the other algorithms at the same time.

The new proposed algorithm is Variable Step size Least Mean Square (VSLMS) which it step size will be vary with the increase in the number of iteration.

The equation of the weights updating for the VSLMS algorithm in MATLAB is

$\mathrm{i}=1: \mathrm{N} ; \% \mathrm{~N}$ is number of iterations

$\mathrm{w}=\mathrm{w}+2 *(\mathrm{mu} / \mathrm{i}) * \mathrm{e}(\mathrm{i}) * \mathrm{x} ; \quad \% \mathrm{mu}$ is initial stepsize

\section{Neural Network}

$\mathrm{NN}$ has become very famous topic of interest since last few years and is being implemented in almost every technological field to solve wide range of problems in an easier and convenient way. The most common neural network model is the Multilayer Perceptron (MLP). This type of neural network is known as a supervised network because it requires a desired output in order to learn. The goal of this type of network is to create a model that correctly maps the input to the output using historical data so that the model can then be used to produce the output when the desired output is unknown [9].

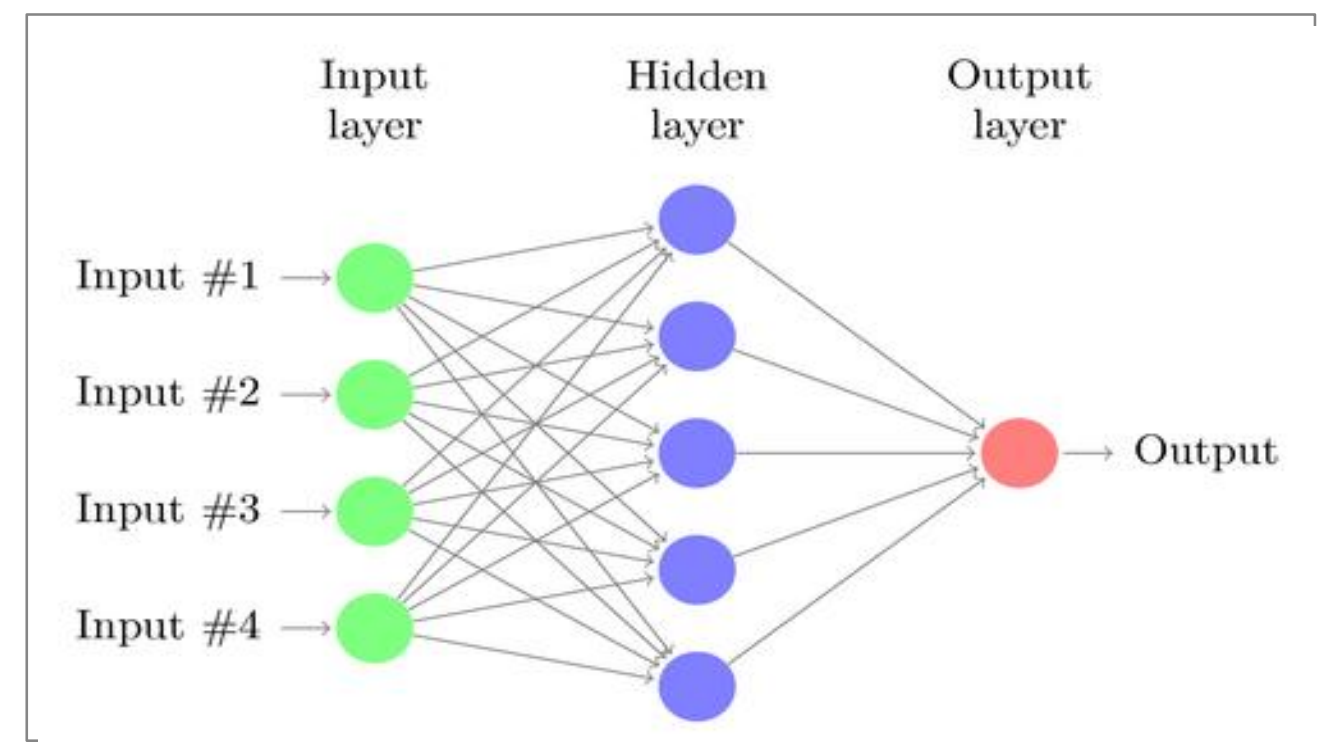

Fig. 3. Adaptive Noise Cancellation system Graphical representation of an MLP

A graphical representation of an MLP is shown in Fig. 3.

A neuron is an information-processing unit that is fundamental to the operation of a neural network. In mathematical terms, we may describe a neuron $i$ by writing the following pair of equations: 
$\mathrm{u}_{\mathrm{i}}=\sum_{\mathrm{j}=1}^{\mathrm{m}} \mathrm{w}_{\mathrm{ij}} \mathrm{x}_{\mathrm{j}}$

Where $\mathrm{m}$ is number of inputs

$y_{i}=f\left(u_{i}+b_{i}\right)$

Where $\mathrm{x}_{1}, \mathrm{x}_{2}, \mathrm{x}_{3}, \ldots, \mathrm{x}_{\mathrm{m}}$ are the input signals; $\mathrm{w}_{\mathrm{i} 1}, \mathrm{w}_{\mathrm{i} 2}, \mathrm{w}_{\mathrm{i} 3}, \ldots, \mathrm{w}_{\mathrm{im}}$ are synaptic weights of neuron $i ; \mathbf{u}_{\mathrm{i}}$ is linear combiner output due the input signals; $\mathrm{b}_{\mathrm{i}}$ is the bias; $\mathrm{f}($.$) is the$ activation function; and $y_{i}$ is the output signal of the neuron [9].

The equation of the activation function in hidden layer for ULNN and UNLNN is

$\mathrm{f}\left(\mathrm{u}_{\mathrm{i}}+\mathrm{b}_{\mathrm{i}}\right)=\tanh \left(\mathrm{a}\left(\mathrm{u}_{\mathrm{i}}+\mathrm{b}_{\mathrm{i}}\right)\right)$

And this activation function is used in output layer for UNLNN but no used in output layer for ULNN.

Back-Propagation algorithm (BP algorithm) is the basic method of training artificial neural network and is been widely used. Take three-forward artificial neural network which the output layer contains only a neuron for example [10].

\section{Simulation Results}

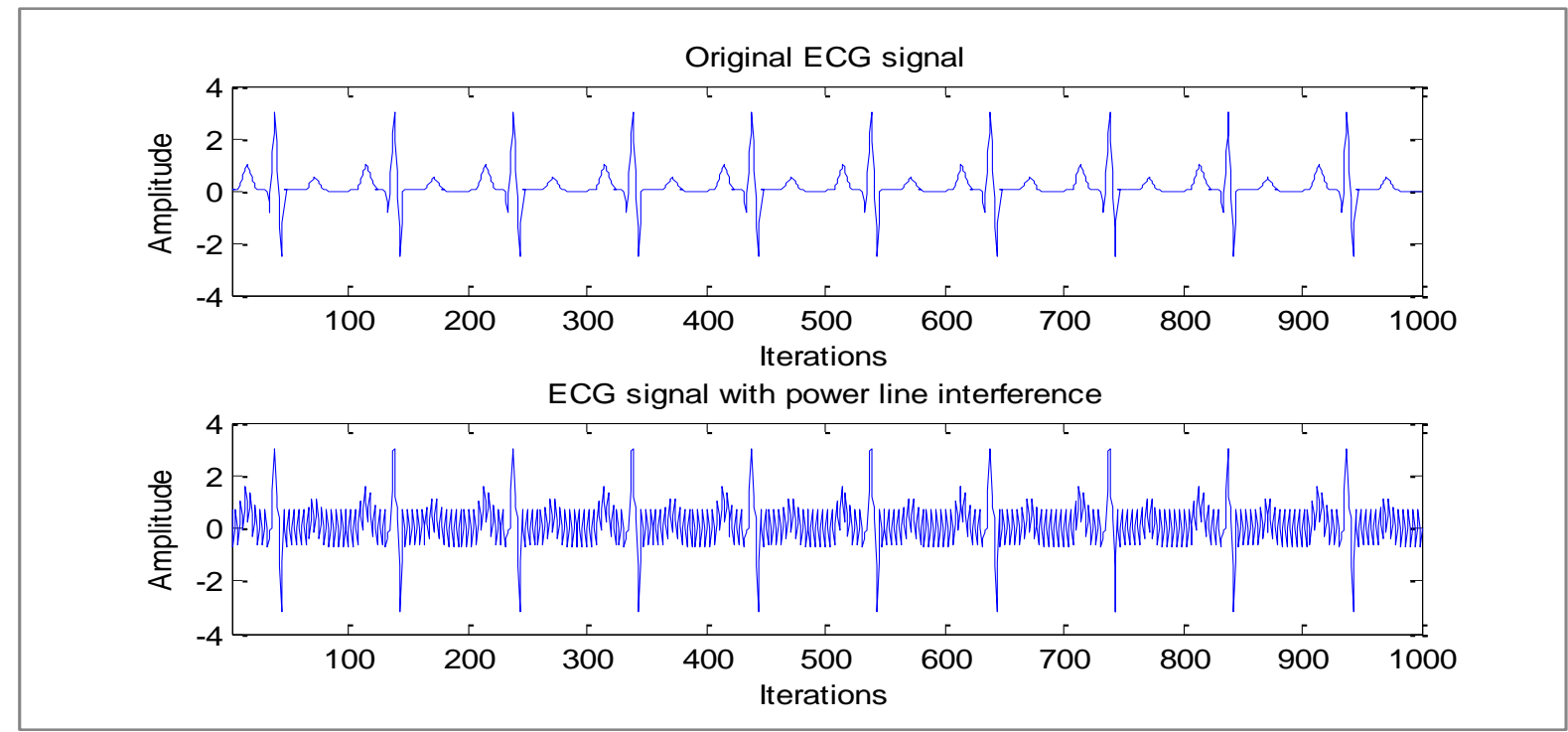

Fig. 4. Complete noise free ECG signal and ECG signal corrupted with Power Line Noise

In the simulation section, it has been generated a noise free ECG signal from ecg function in MATLAB and then mixed the ECG signal with power line signal $50 \mathrm{~Hz}$ as shown in Fig. 4. 


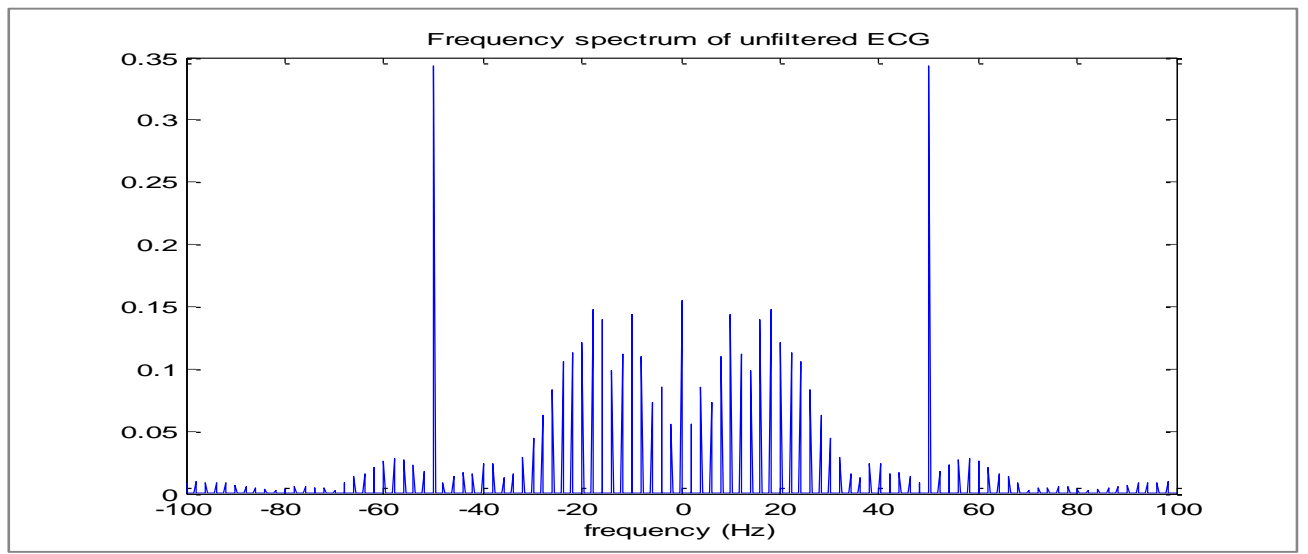

Fig. 5. Frequency spectrum of unfiltered ECG

The ECG signal is very weak time varying signal and has a frequency between $0.5 \mathrm{~Hz}$ to 100 $\mathrm{Hz}$ [11]. The frequency spectrum of unfiltered ECG plot as shown in Fig. 5 has a spike at frequency of $50 \mathrm{~Hz}$ which is an indication of the interference at that frequency.

And after that, the LMS, the SRLMS, the SLMS, the SSLMS and the NLMS algorithms have been used to nullify this noise using the adaptive noise canceller.

The simulation of LMS algorithm was performed with the following specifications: Filter order $\mathrm{M}=18$, step size $\mathrm{mu}=0.015$ and iterations $\mathrm{N}=1000$.

The simulation of SRLMS algorithm was performed with the following specifications: Filter order $\mathrm{M}=18$, step size $\mathrm{mu}=0.008$ and iterations $\mathrm{N}=1000$.

The simulation of SLMS algorithm was performed with the following specifications: Filter order $\mathrm{M}=18$, step size $\mathrm{mu}=0.014$ and iterations $\mathrm{N}=1000$.

The simulation of SSLMS algorithm was performed with the following specifications: Filter order $\mathrm{M}=18$, step size $\mathrm{mu}=0.005$ and iterations $\mathrm{N}=1000$.
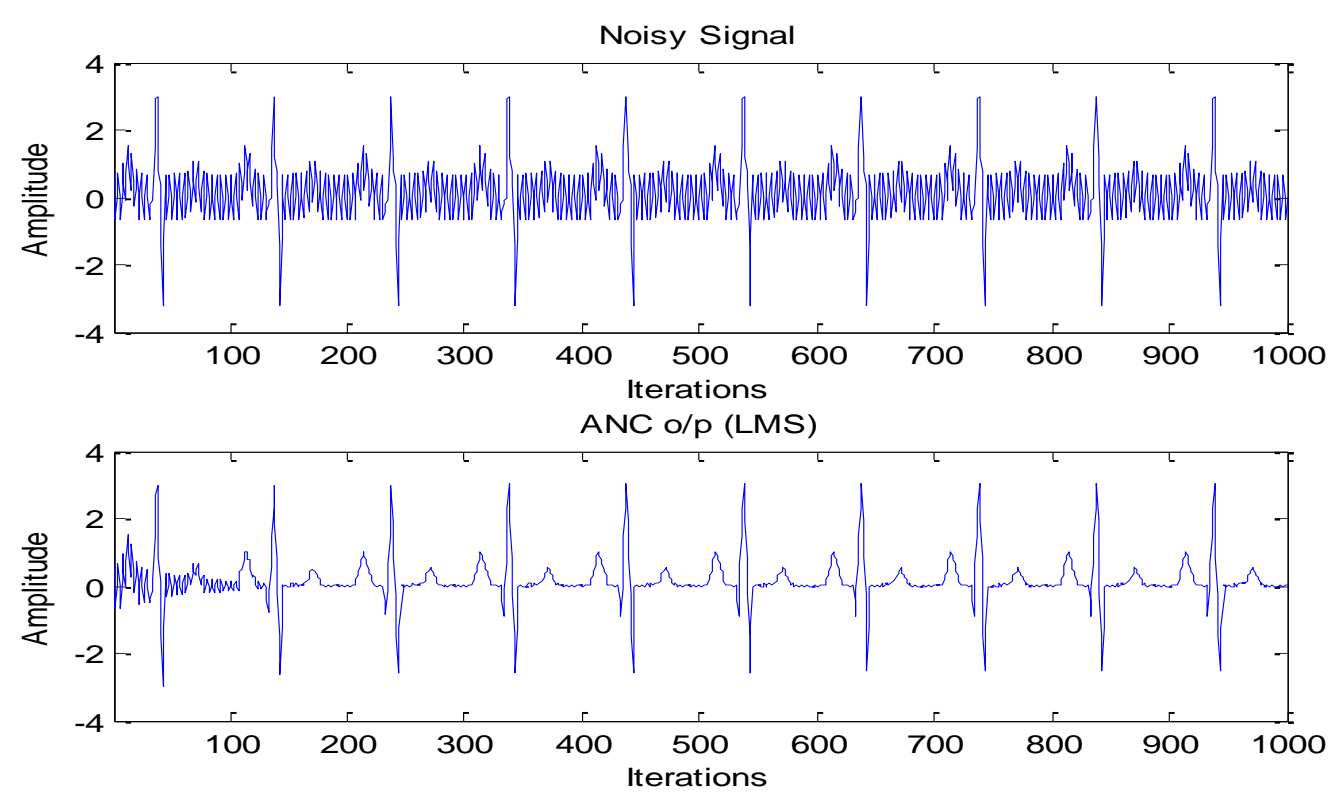

Fig. 6. MATLAB simulation for LMS algorithm 


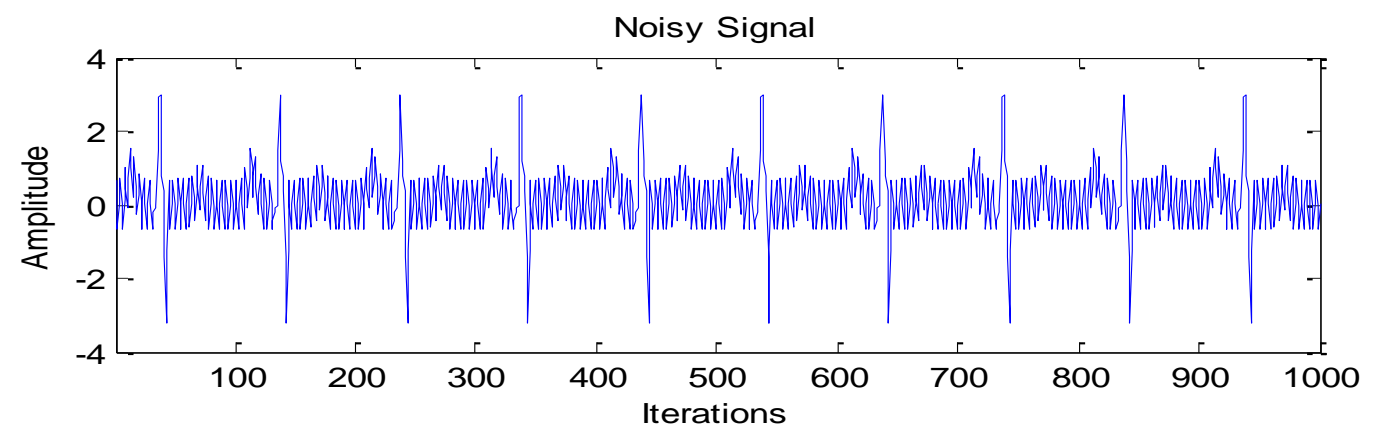

ANC o/p (SRLMS)

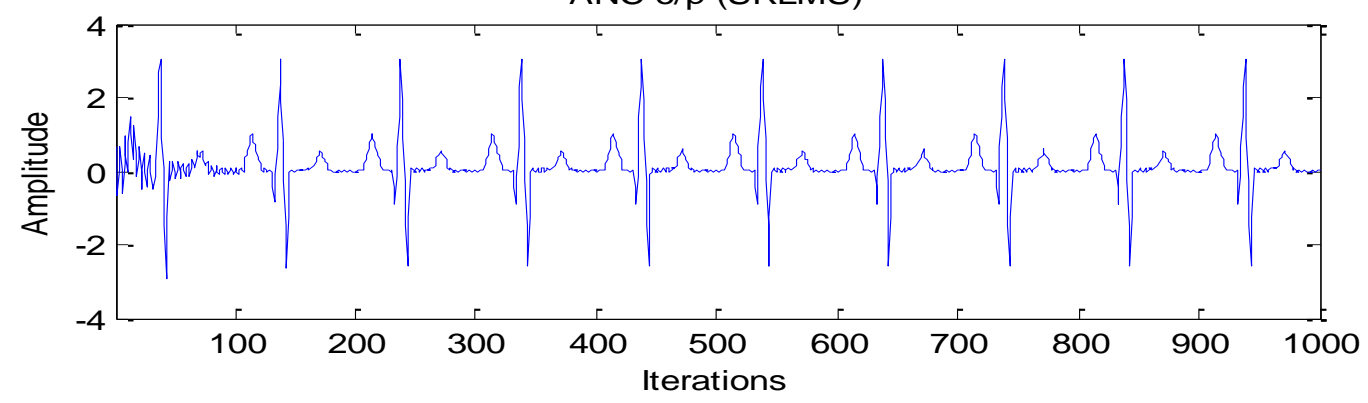

Fig. 7. MATLAB simulation for SRLMS algorithm

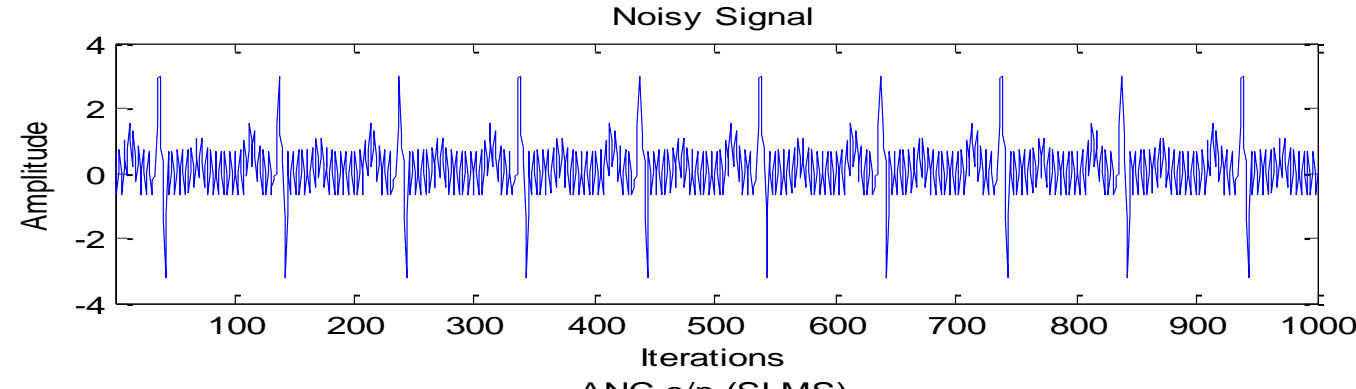

ANC o/p (SLMS)

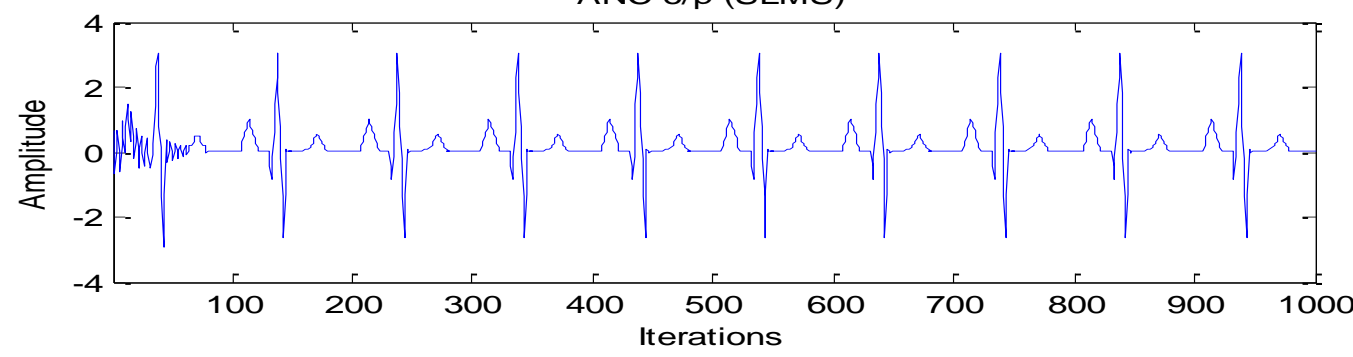

Fig. 8. MATLAB simulation for SLMS algorithm 


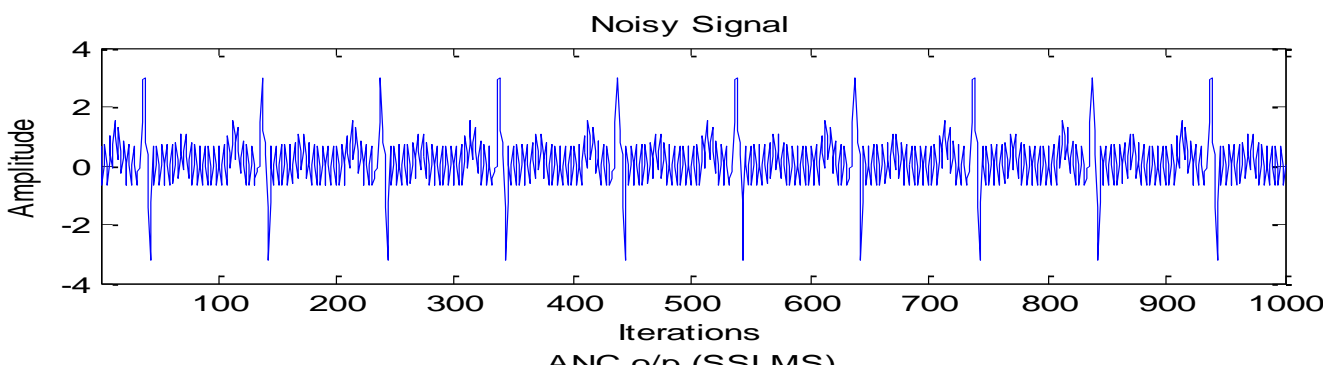

ANC o/p (SSLMS)

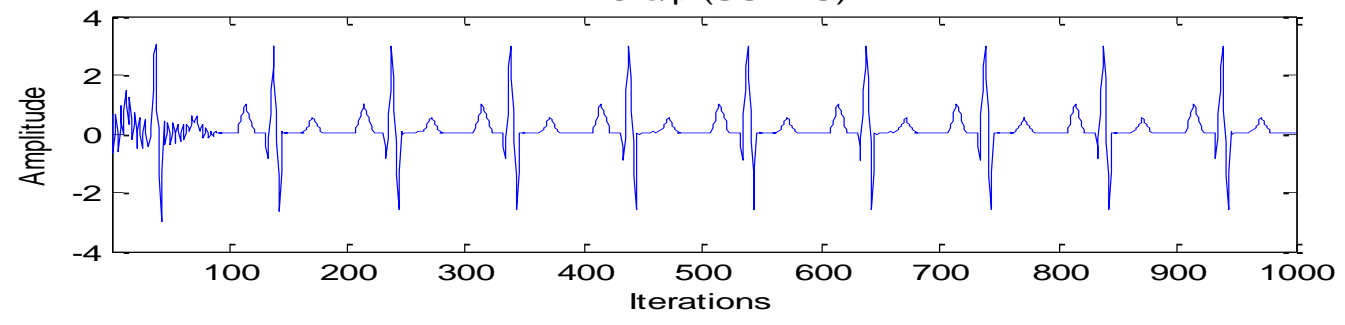

Fig. 9. MATLAB simulation for SSLMS algorithm

The output results for LMS, SRLMS, SLMS and SSLMS algorithms were shown in Fig. 6, Fig. 7, Fig. 8 and Fig. 9 respectively.

The simulation of NLMS algorithm was performed with the following specifications: Filter order $\mathrm{M}=14, \alpha=0.04, \mathrm{c}=0.001$ and iterations $\mathrm{N}=1000$.

The output result for NLMS algorithm was shown in Fig. 10.

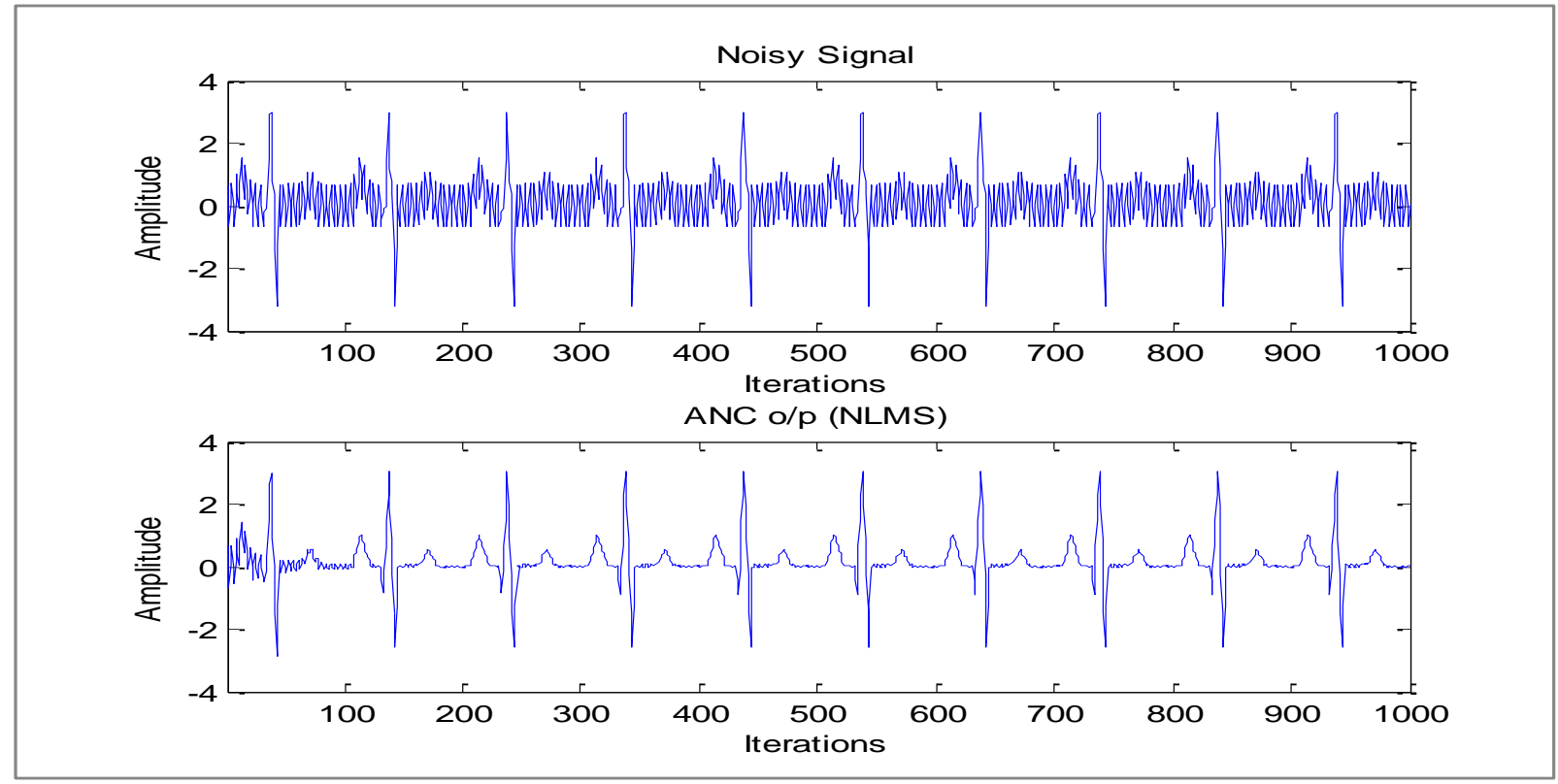

Fig. 10. MATLAB simulation for NLMS algorithm 


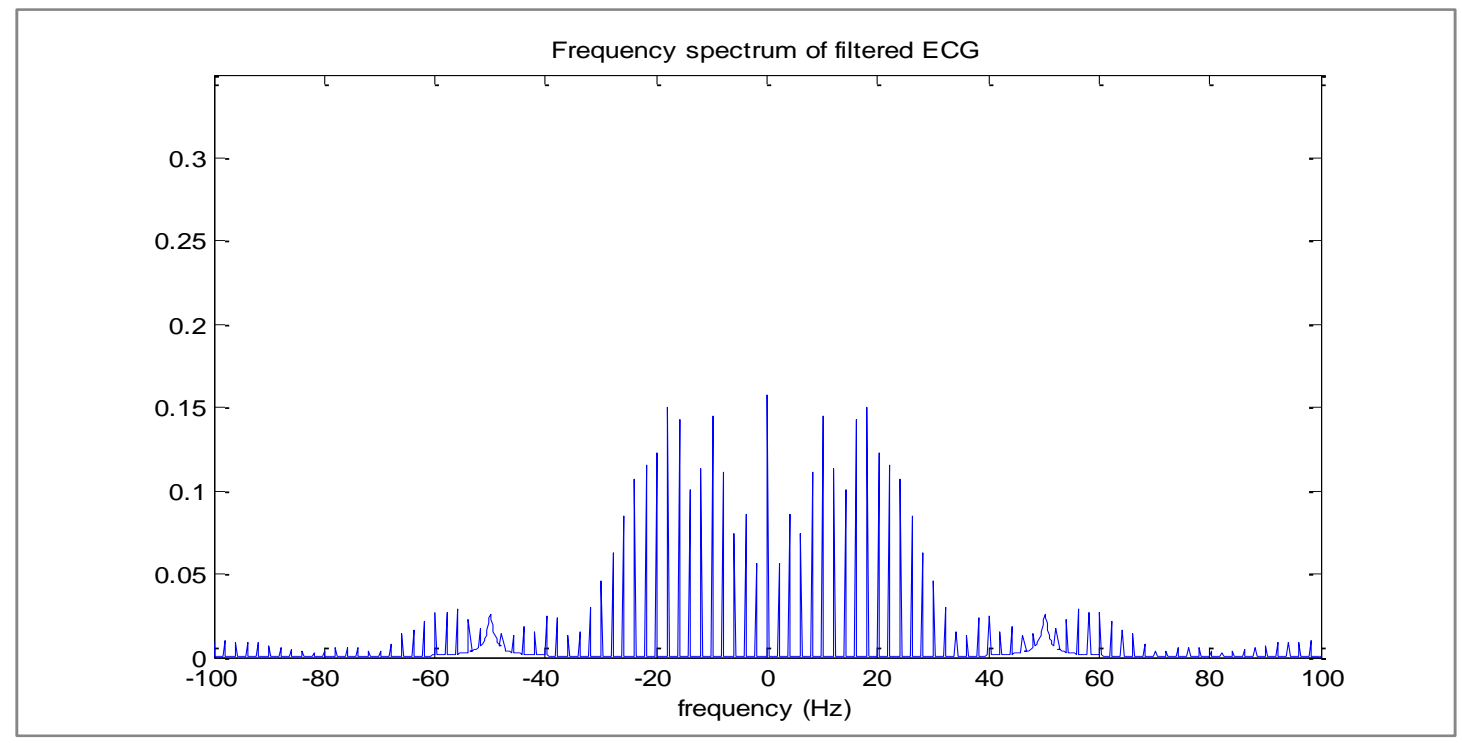

Fig. 11. Frequency spectrum of filtered ECG

The frequency spectrum of filtered ECG plot for adaptive filter is shown in Fig. 11.

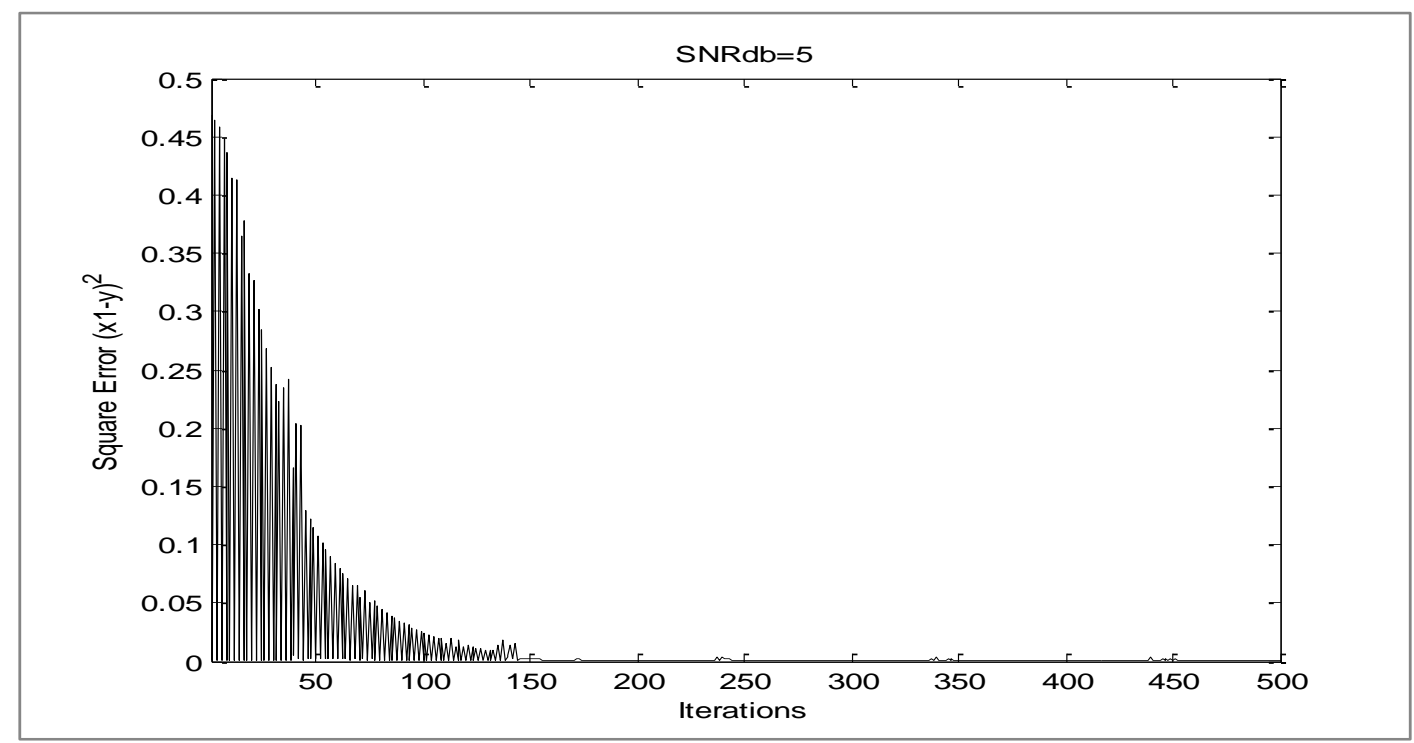

Fig. 12. Square Error of LMS Algorithm 


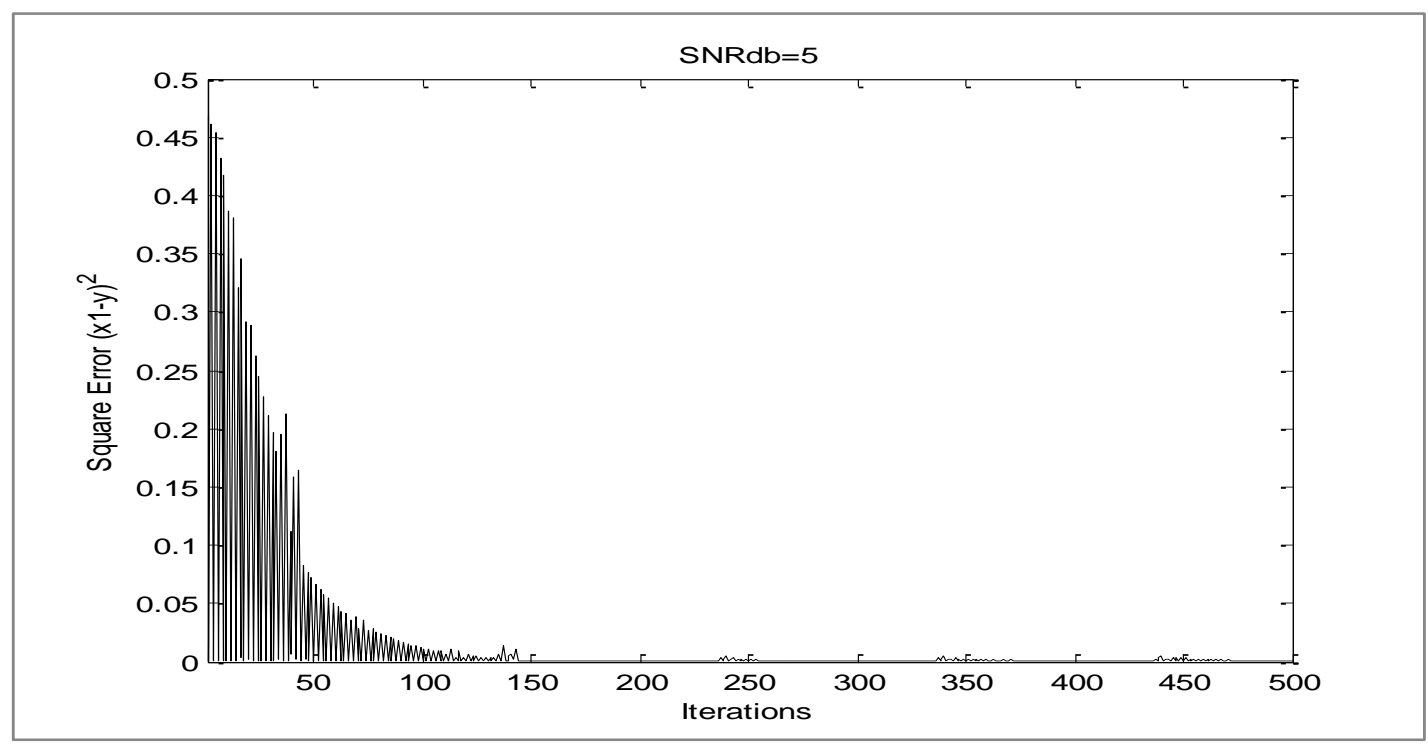

Fig. 13. Square Error of SRLMS Algorithm

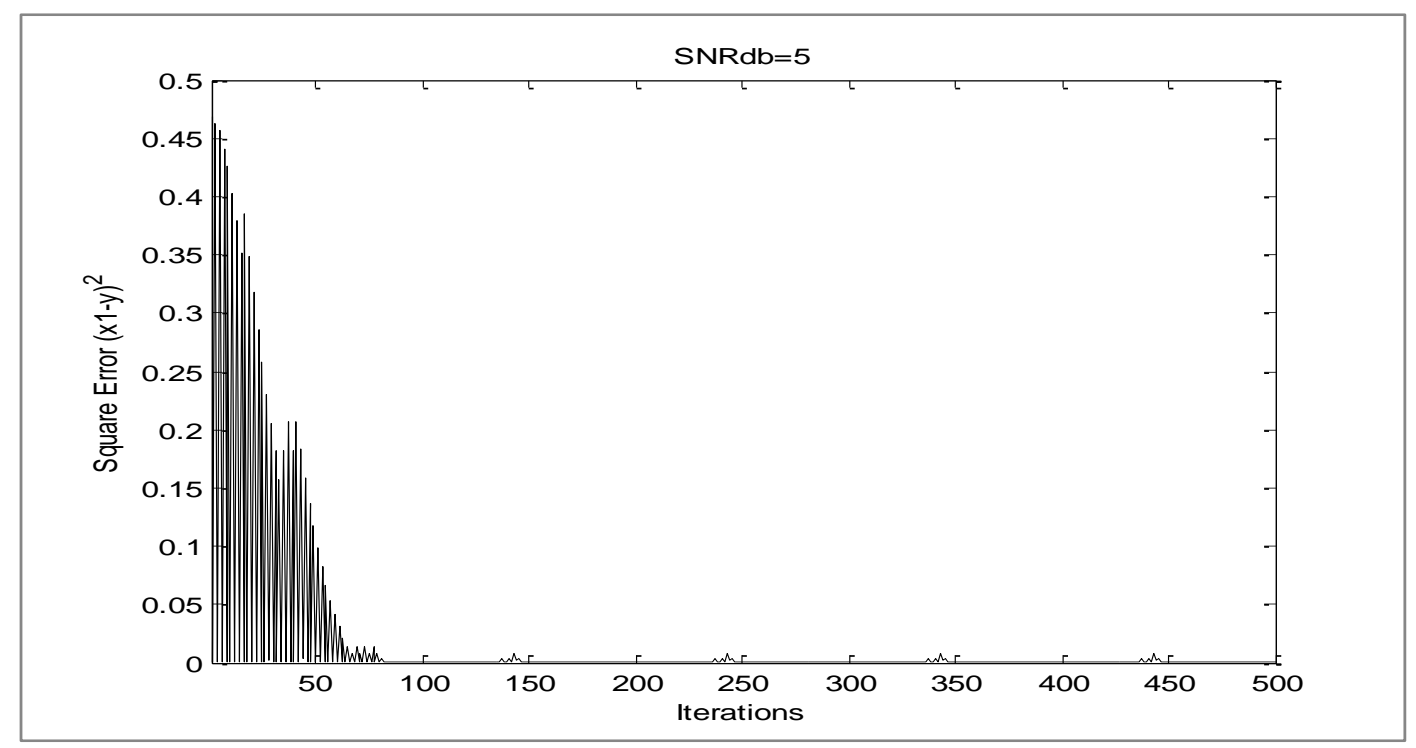

Fig. 14. Square Error of SLMS Algorithm 


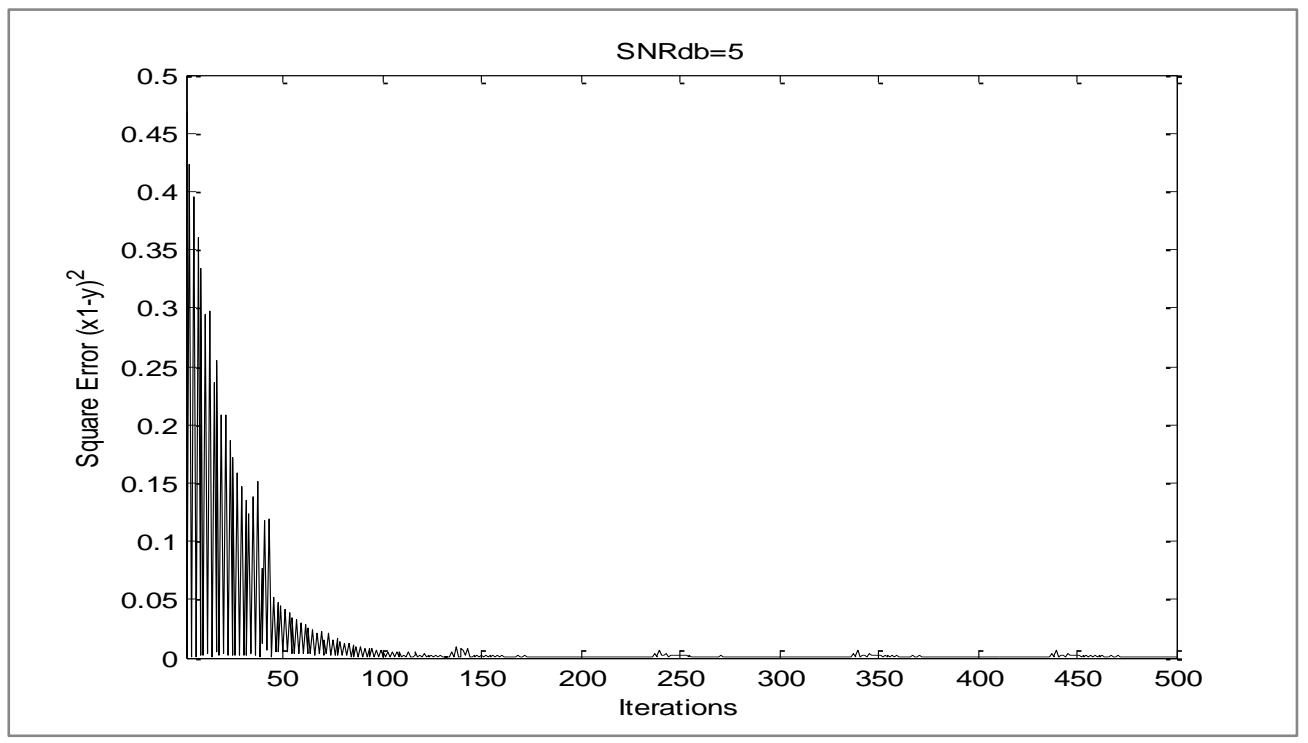

Fig. 15. Square Error of SSLMS Algorithm

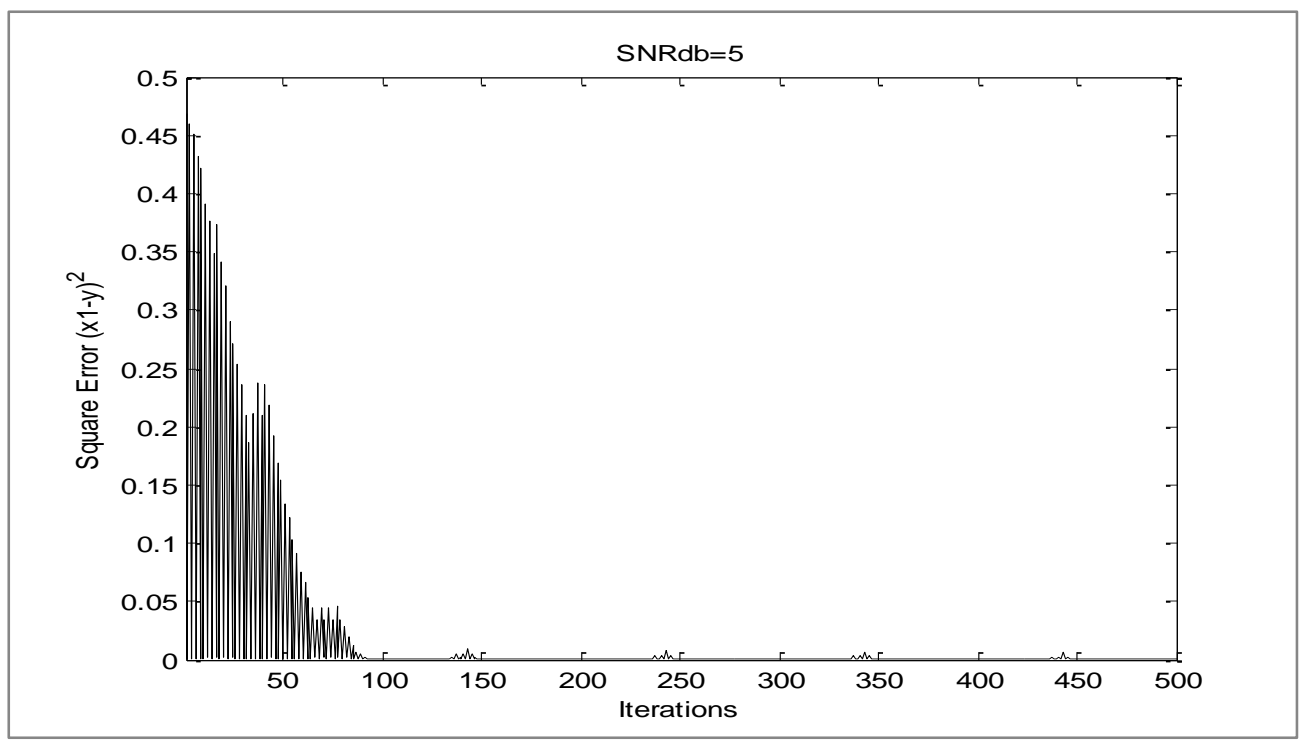

Fig. 16. Square Error of NLMS Algorithm

Square Error (SE) learning curves for these algorithms were shown in Fig. 12, Fig. 13, Fig. 14, Fig. 15 and Fig. 16 respectively.

The simulation of VSLMS algorithm was performed with the following specifications: Filter order $\mathrm{M}=14$, initial step size $\mathrm{mu}=0.95$ and iterations $\mathrm{N}=1000$.

The output result for VSLMS algorithm was shown in Fig. 17. 


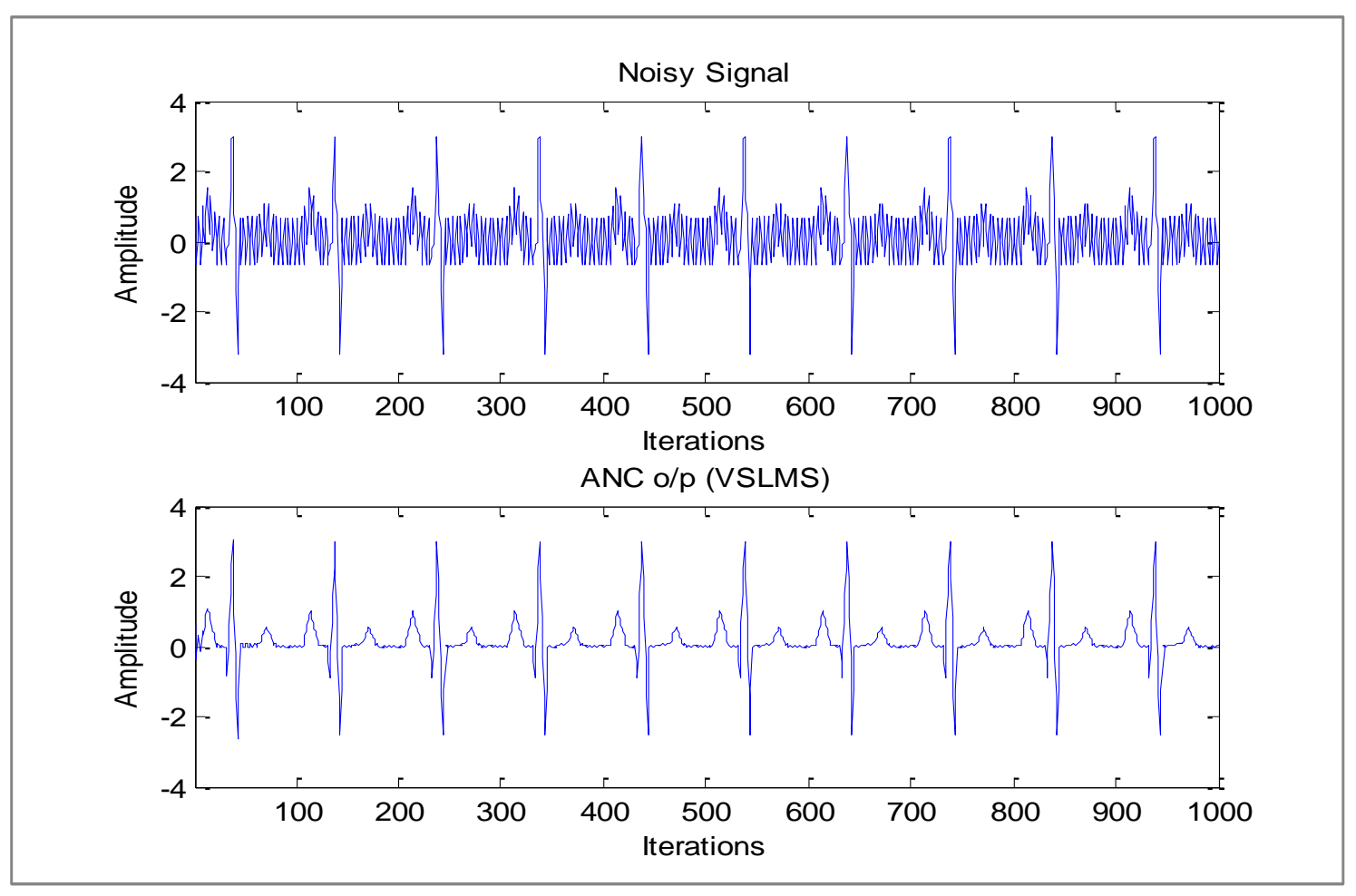

Fig. 17. MATLAB simulation for VSLMS algorithm

SE learning curves for the VSLMS algorithm was shown in Fig. 18.

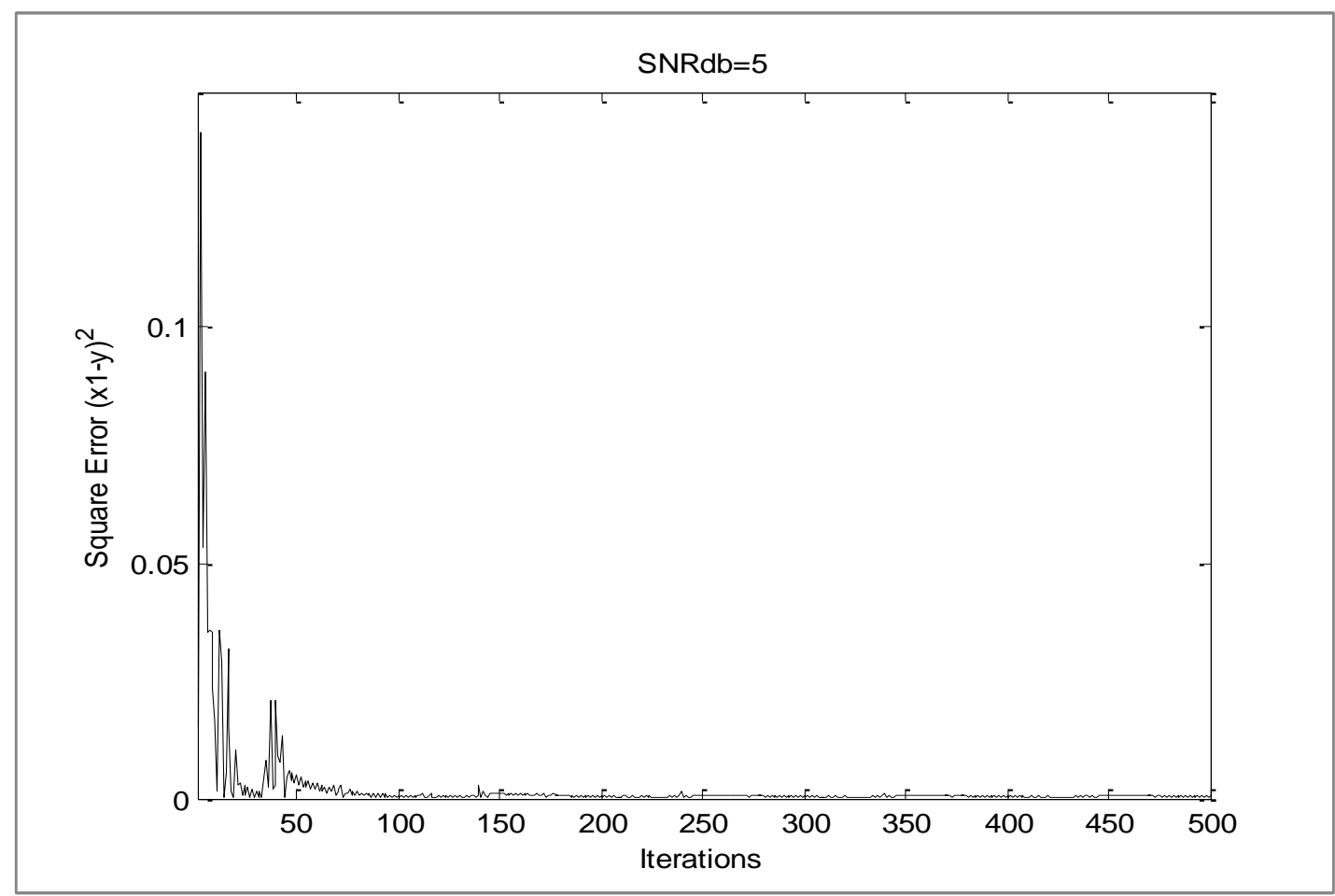

Fig. 18. Square Error of VSLMS Algorithm 
The output result for ULNN and UNLNN were shown in Fig. 19 and Fig. 20.

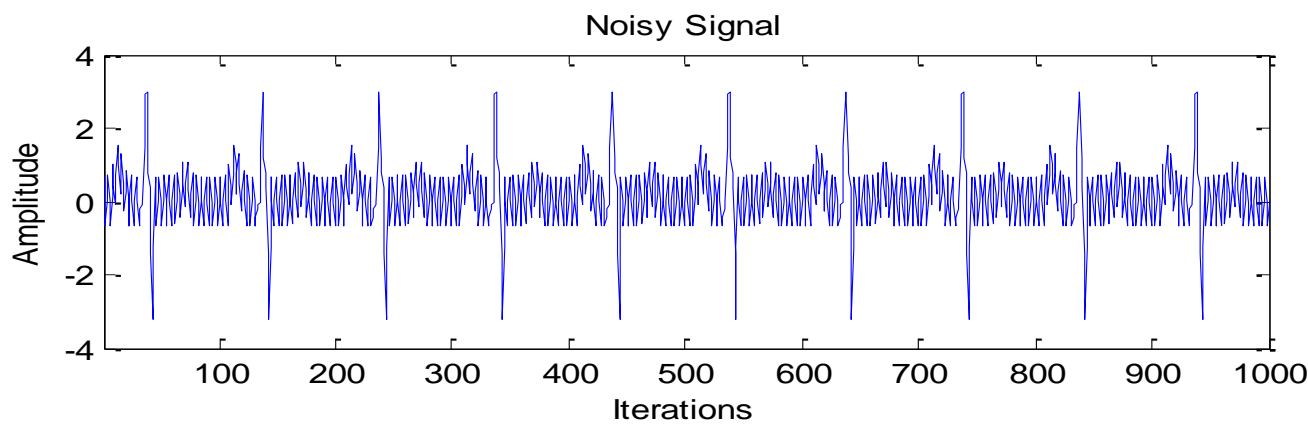

Linear o/p (NN)

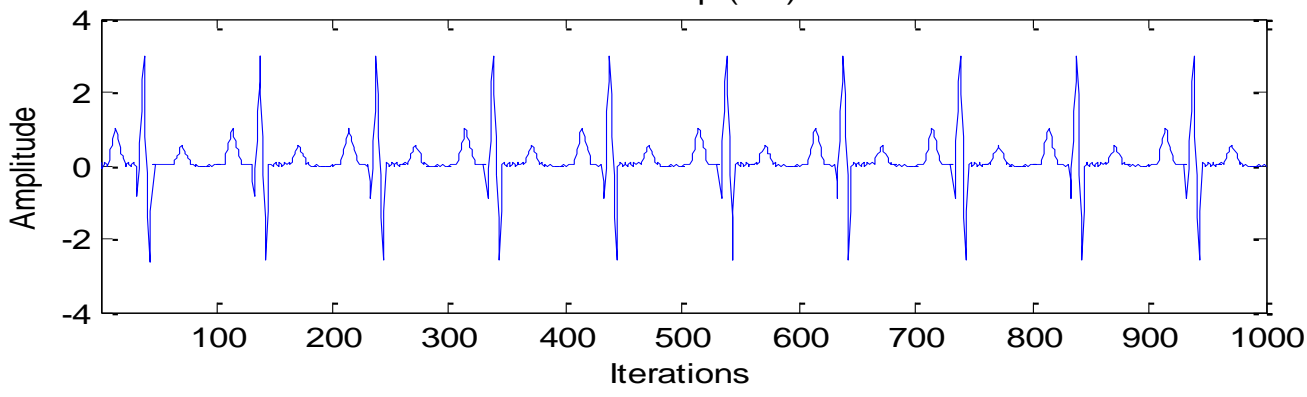

Fig. 19. MATLAB simulation for ULNN

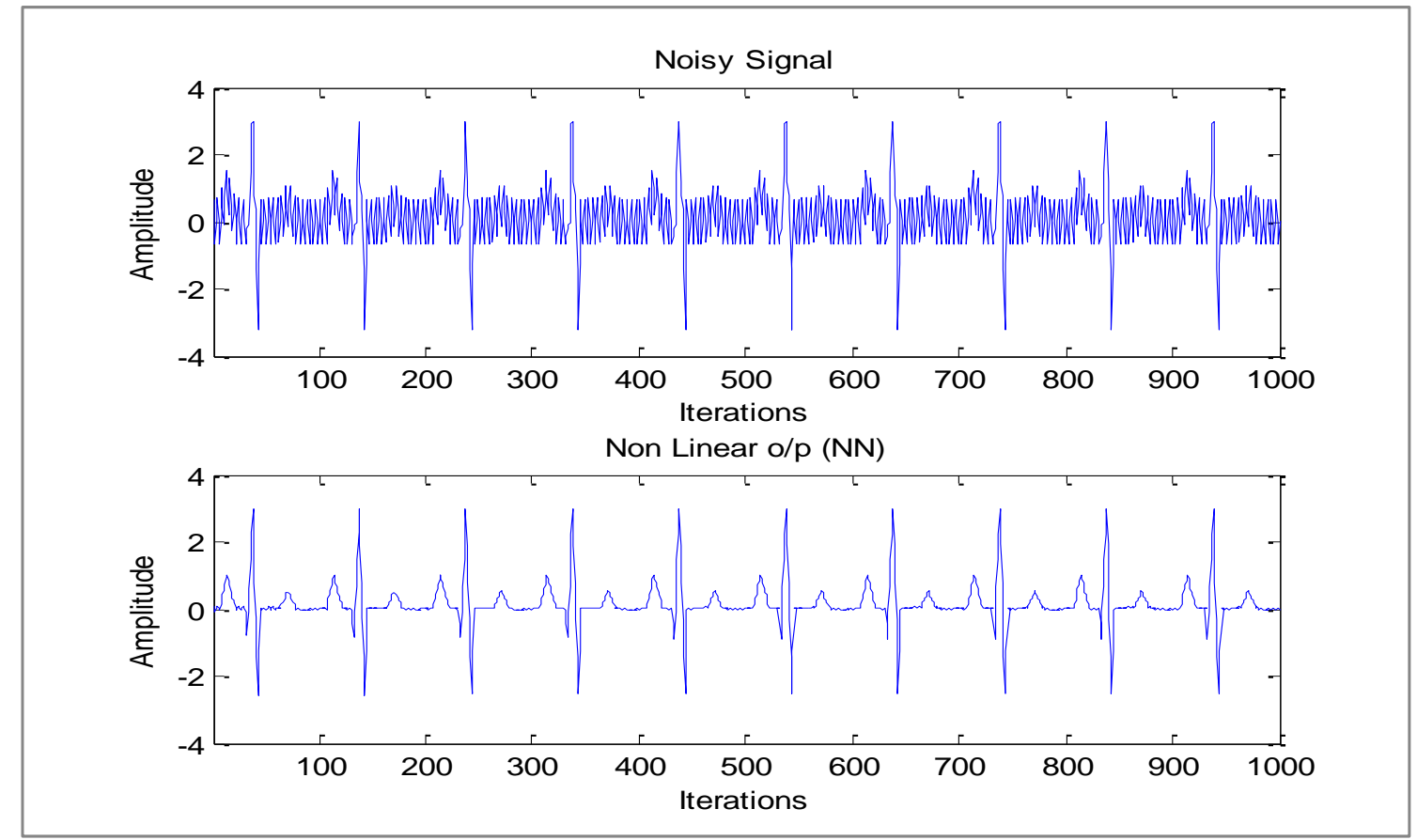

Fig. 20. MATLAB simulation for UNLNN 


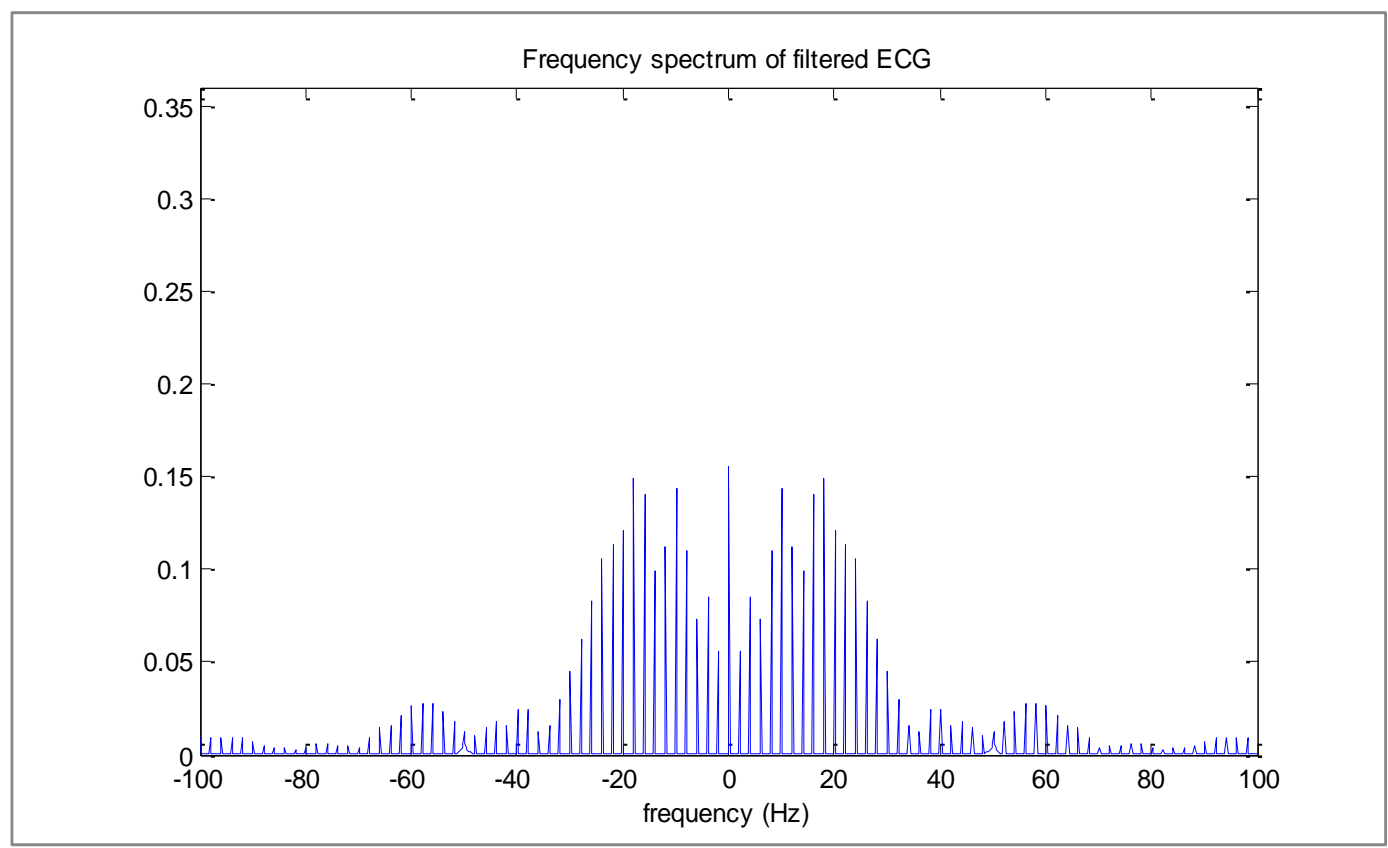

Fig. 21. Frequency spectrum of filtered ECG for NN

The frequency spectrum of filtered ECG plot for NN is shown in Fig. 21.

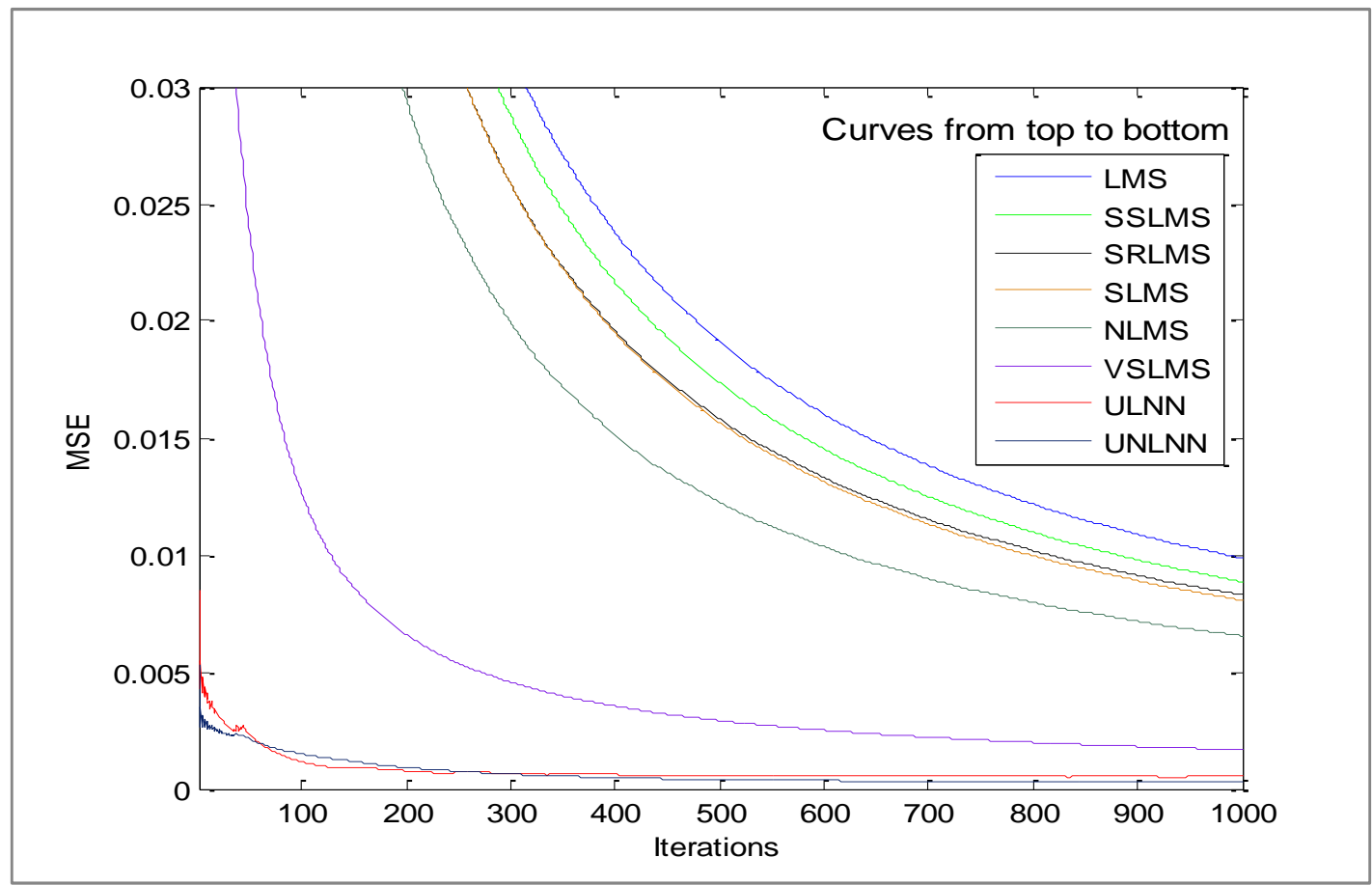

Fig. 22. The convergence rate of all algorithms

Figure 22 shows the result of examining the convergence performance of LMS, SRLMS, SLMS, SSLMS, NLMS, VSLMS algorithms as well as ULNN and UNLNN through the computer simulation. The convergence rate of the ULNN and UNLNN is faster and makes the MSE smaller enough. The convergence rate of the VSLMS algorithm is faster than the LMS, SSLMS, SRLMS, SLMS and NLMS algorithms and makes the MSE smaller than these algorithms. 
Table 1 Performance Comparison of Adaptive Algorithms

\begin{tabular}{|c|c|c|}
\hline \multicolumn{3}{|c|}{ This work with $\mathrm{SNR}=5 \mathrm{~dB}$} \\
\hline \multicolumn{3}{|c|}{ Filter order $\mathrm{M}=18$ and iterations $\mathrm{N}=1000$. } \\
\hline Algorithm & tep Size muS & MSE \\
\hline LMS & 0.015 & 0.0099 \\
\hline SSLMS & 0.005 & 0.0089 \\
\hline SRLMS & 0.008 & 0.0083 \\
\hline SLMS & 0.014 & 0.0081 \\
\hline \multicolumn{3}{|c|}{$\begin{array}{c}\text { Filter order } M=14, \alpha=0.04, c=0.001 \text { and } \\
\text { iterations } N=1000\end{array}$} \\
\hline Algorithm & \multicolumn{2}{|c|}{ MSE } \\
\hline NLMS & \multicolumn{2}{|c|}{0.0065} \\
\hline \multicolumn{3}{|c|}{$\begin{array}{c}\text { Filter order } \mathrm{M}=14 \text {, initial step size } \mathrm{mu}=0.95 \\
\text { and iterations } \mathrm{N}=1000\end{array}$} \\
\hline Algorithm & \multicolumn{2}{|c|}{ MSE } \\
\hline VSLMS & \multicolumn{2}{|c|}{0.0017} \\
\hline \multicolumn{3}{|c|}{ Number of Inputs in Neural Network $M=1$} \\
\hline $\begin{array}{l}\text { Type of } \\
\text { NN }\end{array}$ & $\begin{array}{l}\text { Hidden Layer } \\
\text { Neurons HLN }\end{array}$ & MSE \\
\hline ULNN & 7 & 0.00052 \\
\hline UNLNN & 14 & 0.0003 \\
\hline
\end{tabular}

In Table 1 performance analysis of all algorithms is presented in term of MSE for $\mathrm{SNR}=5 \mathrm{~dB}$. Table 2 Performance Comparison of Adaptive Algorithms

This work with $\mathrm{SNR}=10 \mathrm{~dB}$

Filter order $\mathrm{M}=18$ and iterations $\mathrm{N}=1000$.

\begin{tabular}{c|c|c}
\hline Algorithm & tep Size muS & MSE \\
\hline LMS & 0.02 & 0.0071 \\
\hline SSLMS & 0.005 & 0.0059 \\
\hline SRLMS & 0.009 & 0.0057 \\
\hline SLMS & 0.02 & 0.0052 \\
\hline
\end{tabular}

Filter order $\mathrm{M}=14, \alpha=0.035, \mathrm{c}=0.001$ and iterations $\mathrm{N}=1000$

\begin{tabular}{c|c}
\hline Algorithm & MSE \\
\hline NLMS & 0.0046 \\
\hline
\end{tabular}

Filter order $\mathrm{M}=14$, initial step size $\mathrm{mu}=0.93$ and iterations $\mathrm{N}=1000$

\begin{tabular}{c|c|c}
\hline Algorithm & \multicolumn{2}{|c}{ MSE } \\
\hline VSLMS & \multicolumn{2}{|c}{0.0013} \\
\hline \multicolumn{2}{c}{ Number of Inputs in Neural Network M=1 } \\
\hline $\begin{array}{c}\text { Type of } \\
\text { NN }\end{array}$ & $\begin{array}{c}\text { Hidden Layer } \\
\text { Neurons HLN }\end{array}$ \\
\hline ULNN & 7 & MSE \\
\hline UNLNN & 13 & 0.00033 \\
\hline \hline
\end{tabular}

In Table 2 performance analysis of all algorithms is presented in term of MSE for $\mathrm{SNR}=10$ dB. 
Table 3 Performance Comparison of Adaptive Algorithms

\begin{tabular}{|c|c|c|}
\hline \multicolumn{3}{|c|}{ This work with $\mathrm{SNR}=15 \mathrm{~dB}$} \\
\hline \multicolumn{3}{|c|}{ Filter order $\mathrm{M}=18$ and iterations $\mathrm{N}=1000$. } \\
\hline Algorithm & tep Size muS & MSE \\
\hline LMS & 0.035 & 0.0043 \\
\hline SSLMS & 0.006 & 0.0037 \\
\hline SRLMS & 0.01 & 0.0039 \\
\hline SLMS & 0.03 & 0.0036 \\
\hline \multicolumn{3}{|c|}{$\begin{array}{c}\text { Filter order } \mathrm{M}=14, \alpha=0.035, \mathrm{c}=0.001 \text { and } \\
\text { iterations } \mathrm{N}=1000\end{array}$} \\
\hline Algorithm & \multicolumn{2}{|c|}{ MSE } \\
\hline NLMS & \multicolumn{2}{|c|}{0.0030} \\
\hline \multicolumn{3}{|c|}{$\begin{array}{c}\text { Filter order } \mathrm{M}=14 \text {, initial step size } \mathrm{mu}=0.89 \\
\text { and iterations } \mathrm{N}=1000\end{array}$} \\
\hline Algorithm & \multicolumn{2}{|c|}{ MSE } \\
\hline VSLMS & \multicolumn{2}{|c|}{0.0010} \\
\hline \multicolumn{3}{|c|}{ Number of Inputs in Neural Network $M=1$} \\
\hline $\begin{array}{l}\text { Type of } \\
\text { NN }\end{array}$ & $\begin{array}{l}\text { Hidden Layer } \\
\text { Neurons HLN }\end{array}$ & MSE \\
\hline ULNN & 7 & 0.00023 \\
\hline UNLNN & 13 & 0.00012 \\
\hline
\end{tabular}

In Table 3 performance analysis of all algorithms is presented in term of MSE for $S N R=15$ $\mathrm{dB}$.

\section{Conclusion}

The main purpose of this paper was to study performance of the adaptive noise canceller for various adaptive algorithms and NN which were used in de-noising an ECG signal. These results show that the LMS algorithm has slow convergence but simple to implement and gives good results if step size is chosen correctly. The noise cancellation performance of NLMS was observed consistently better compared with LMS, SRLMS, SSLMS and SLMS algorithms. The results show that the step iteration changeable algorithm that was improved in this paper can remove power line frequency interference of $50 \mathrm{~Hz}$ effectively compared with other algorithms of adaptive filter and can be fast in the error convergence rate. The performance of ULNN and UNLNN was the best performance for cancelling the ECG noise and has very low MSE.

\section{References}

[1] Islam, S. Z., Jidin, R. and Ali, M., "Performance study of adaptive filtering algorithms for noise cancellation of ECG signal," in Information, Communications and Signal Processing, 2009. ICICS 2009. 7th International Conference on, 2009, pp. 1-5.

[2] Widrow, B., Glover, J. R., McCool, Jr., J. M., Kaunitz, J., Williams, C. S., Hearn, R. H., et al., "Adaptive noise cancelling: Principles and applications," Proceedings of the IEEE, vol. 63, pp. 1692-1716, 1975. 
[3] Benesty, J., Amand, F., Gilloire, A. and Grenier, Y., "Adaptive filtering algorithms for stereophonic acoustic echo cancellation," in Acoustics, Speech, and Signal Processing, 1995. ICASSP-95., 1995 International Conference on, 1995, pp. 3099-3102 vol.5.

[4] Haykin, S., Adaptive Filter Theory, $3^{\text {rd }}$ ed., New Jersey: Prentice-Hall, 1996.

[5] Dhubkarya, D. C., Katara, A. and Thenua, R. K., "Simulation of Adaptive Noise Canceller for an ECG signal Analysis," ACEEE Int. J. on Signal \& Image Processing, vol. 03, no. 01, Jan 2012, pp.1-4.

[6] Diniz, P. S. R., Adaptive Filtering: Algorithms and Practical Implementations, ISBN 978-0-387-31274-3, Kluwer Academic Publisher (C) 2008 Springer Science+Business Media, LLC, pp.77-195.

[7] Widrow, B. and Stearns, S. D., Adaptive Signal Processing, Prentice-Hall, Englewood Cliffs, New Jersy, 1985.

[8] Sankar, A. B., Kumar, D. and Seethalakshmi, K., "Performance study of various adaptive algorithms for noise cancellation in Respiratory signals", Signal Processing: An international journal (SPIJ), vol. 04, issue (5), pp. 267-278.

[9] Haykin, S., Neural Networks: A Comprehensive Foundation: Prentice Hall, 1999.

[10] Tian, Z.-M. and Wang, A.-Z., "The Research of Adaptive Noise Cancellation Technology Based on Neural Network," in Computing, Measurement, Control and Sensor Network (CMCSN), 2012 International Conference on, 2012, pp. 144-147.

[11] Rangayyan, R. M., Biomedical Signal Analysis: A Case-Study Approach, New York, NY: Wiley, 2002, ch. 1. 